\title{
UMA SOLUÇÃO POSSÍVEL PARA A INDISCIPLINA: A AVALIAÇÃO
}

Ângela Luzia Flain Ferreira angelaflainfer@yahoo.es

\section{RESUMO}

Este artigo tem por objetivo refletir sobre a forma como a avaliação está sendo aplicada na escola e as possíveis causas da indisciplina em sala de aula. $\mathrm{O}$ que se constata, hoje, é um distanciamento entre o que propõe a legislação e o uso da avaliação, e a indisciplina se transforma num fator crescente que prejudica a aprendizagem e desestabiliza as relações em sala de aula. Acreditamos que uma solução possível para os problemas de indisciplina, seria o uso efetivo da avaliação, preponderantemente, qualitativa, levando alunos e professores a refletirem sobre a sua prática, porque é só através da reflexão que se pode chegar a mudanças de atitude.

\section{A AVALIAÇÃO HOJE}

A avaliação faz parte da nossa vida diária. Consiste em um processo de reflexão e tomada de decisões, de acordo com os nossos propósitos. Para isso, não utilizamos notas nem conceitos, avaliamos e realizamos escolhas que se efetivarão em mudanças ou atitudes que considerarmos necessárias. Isso ocorre desde as mais simples decisões, como, por exemplo, qual roupa vestir, até as mais importantes, como a carreira que vamos seguir.

No ensino formal, a avaliação também é uma constante, acompanhando toda a vida do estudante, porém, neste contexto, ela se diferencia. Apresenta-se através de notas ou conceitos, quando o aluno não é o sujeito da sua própria avaliação, pois, normalmente, sofre o processo avaliativo, sendo que nem sempre o ato de avaliar está relacionado a uma mudança de comportamento ou atitude por parte do professor ou do aluno. A lei de Diretrizes e Bases da Educação prevê que aluno deverá ser avaliado de forma contínua e cumulativa, prevalecendo o aspecto qualitativo sobre o quantitativo da aprendizagem. Lei $n^{\circ}$ 9.394/96, de Diretrizes e Bases da Educação.

As dimensões qualitativas e qualitativas referem-se ao mesmo fenômeno a ser medido, controlado e acompanhado. A primeira diz em conceitos ou notas a intensidade com que atributos da segunda se manifestam no fenômeno 
mensurado. Na realidade, a avaliação qualitativa confere significado e esclarece a quantitativa, conforme. SANT'ANA(1997:p.78).

O aspecto qualitativo, que deve ser preponderante nos resultados da avaliação, sofre múltiplas interpretações pelos professores, comprometendo o que foi estabelecido por lei. Como esclarece HOFFMANN (1998:p.38), analisar aspectos qualitativos do desempenho do aluno não é o mesmo que analisar suas atitudes e comportamentos na escola. Seria temeroso aprovar um aluno porque ele é bem-comportado, colaborador e esforçado, mesmo que ele não tenha atingido os requisitos mínimos para a próxima série. De acordo com a mesma autora (idem:39-41), avaliar sob o aspecto qualitativo significa observar e interpretar de forma consistente as manifestações do aluno, o que vai muito além dos sinais de "mais ou menos" que o aluno recebe pelas suas atitudes ou da pontuação atingida em suas atividades de aprendizagem.

A análise qualitativa, entendida como a descrição do nível de compreensão do aluno a respeito de uma determinada área de conhecimento, tanto pode ser feita em relação às suas atitudes como em relação às suas possibilidades cognitivas, fornecendo os subsídios necessários para a continuidade do processo educativo. Então, se esses resultados fossem discutidos com os alunos e juntos buscassem soluções para as dificuldades encontradas nos dois aspectos, estaríamos diante da solução ideal, em que o aluno, através da reflexão, seria o sujeito do próprio processo educativo. É claro que em um determinado momento a avaliação terá de demonstrar, através de conceitos ou notas, o que o aluno aprendeu, embora esse não seja o seu principal objetivo.

Longe do ideal, o que se percebe, na maioria das escolas, é que prevalece na avaliação o aspecto quantitativo, no qual, através de notas ou conceitos, o aluno é aprovado ou não. Assim, de acordo com LUCKESI (1999:p.35), a ação avaliativa é utilizada com a função de classificar e não de diagnosticar, quando na realidade, o julgamento de valor deveria possibilitar uma nova tomada de decisão sobre o objeto avaliado. Na função classificatória, a avaliação se transforma em um instrumento estático que impede o crescimento, enquanto que, na função diagnóstica, ela se constitui em um momento dialético no processo 
de avançar no desenvolvimento da ação e do crescimento, rumo à autonomia e à competência. Para o aspecto qualitativo, são reservados alguns pontos que o aluno vai conseguir se realizar as tarefas e se mantiver atitudes adequadas para uma sala de aula, como por exemplo manter-se calado durante a explicação, não se levantar da cadeira, não usar boné, etc.

Avaliar somente sob o aspecto quantitativo, a princípio, pode levar o professor a sentir-se mais seguro em relação ao fato de estar sendo justo ao avaliar, devido à noção de precisão que fornecem as notas obtidas em testes e provas. Porém, para HOFFMANN (1998:p.61): "em nome da justiça da precisão o professor nunca foi tão injusto". Isso porque, segundo a autora, à medida que as crianças realizam suas tarefas, elas efetivam muitas conquistas, refletem sobre as suas hipóteses, discutem com os pais ou colegas, justificam suas alternativas, enfim, o aprendizado é um processo dinâmico que a concepção constatativa da testagem não consegue abarcar, pois desconsidera a importância da interação entre os próprios alunos e entre eles e o professor, bem como da argumentação e .da reflexão conjunta.

Mesmo que essa seja a prática que prevalece na maioria das escolas, há muitos professores que se incomodam com a possibilidade de ser injustos ao avaliar e na tentativa de mudar. Esclarecem quais os objetivos a serem alcançados, comunicam quais os critérios que utilizarão como parâmetro de avaliação, exigem do aluno na mesma medida em que proporcionam subsídios para a aprendizagem, discutem com eles os resultados obtidos e buscam juntos formas de superar as dificuldades, através de novas oportunidades como, por exemplo, trabalhos extras ou recuperação paralela - tudo em relação ao aspecto cognitivo; mas como isso fica em relação às atitudes e à disciplina? Muitas são as queixas dos professores em relação a esses aspectos, ou melhor, à falta deles, sendo que a solução adequada não parece clara.

A escola tenta controlar a indisciplina usando a punição, seja através de notas, repreensões orais e escritas ou suspensões, o que não vem se mostrando eficiente como alternativa de solução, considerando os problemas crescentes nesse aspecto, em grande parte das escolas. Realmente esse controle não é 
tarefa fácil, se consideramos o contexto em que estão inseridos professor e aluno. São, em média, quarenta alunos em sala de aula, sendo que grande parte deles, inquietos, indisciplinados e até agressivos. Esse comportamento, que antes era privilégio dos adolescentes, o que é compreensível na sua faixa etária, hoje se estende tanto para as primeiras séries como para o ensino secundário. MENEGOLLA (1992:p.20-21) descreve, da mesma forma, a situação de alunos e professores, quando diz que o toque da campainha não é suficiente para acalmar os alunos. Muitas vezes, gritos são necessários para que se consiga iniciar a aula, e as interrupções provocadas para acalmar a bagunça formam um ritual que se tornou um ato pedagógico. Diante dessa situação, na qual o professor explica e não é entendido, fala e não é ouvido, se estabelece um desequilíbrio: as relações se desfazem, e o desentendimento passa a ser normal, caracterizando o nosso tipo de escola como massificante e desumana.

Muitas vezes, a escola não tem condições físicas de oferecer atividades variadas e estimulantes, semelhantes àquelas com que o aluno está acostumado no seu dia-a-dia, como televisão, computador, vídeo e internet. Assim, o quadro negro e o giz lhe parecem por demais cansativos. Alguns enfrentam problemas familiares e, muitas vezes, não estão acostumados a assumir responsabilidades e a respeitar normas de comportamento. Somando-se a isso, o professor tem um programa a ser cumprido, uma carga de trabalho às vezes, desumana, não tem tempo de refletir sobre a sua atuação profissional, assim como não tem tempo para aprimorar-se profissionalmente. Só esses já são ingredientes suficientes para gerar conflitos em sala de aula. Nesse contexto, é possível entender a dificuldade do professor em refletir com os alunos sobre o que acontece na aula, mesmo porque essa não é uma prática comum na maioria das escolas, e é consenso que a formação de hábitos e atitudes é obrigação da família. Então, a saída é punir e, quando todas as punições forem esgotadas, transfere-se o aluno de escola e tudo começa outra vez, sem que haja uma mudança no comportamento do aluno ou da escola.

\section{A INDISCIPLINA: QUEM É RESPONSÁVEL POR ELA?}


Para MENGOLLA (1992:p.19), "Nossa escola comum, em geral, é um lugar sem alegria, onde a algazarra é a tônica predominante". Para o autor, a escola parece ser um ambiente adequado para manifestar o desatino psicológico criado pela angústia da modernidade social e familiar; com o surgimento da mentalidade de que tudo se deve fazer, tudo deve ser renovado, criam-se novos estilos de vida. E a escola, inserida nesse meio, parece estar sendo usada pelas crianças e jovens para liberar suas neuroses, acumuladas junto à família e à sociedade.

A indisciplina que antes, época em que se adotava a pedagogia tradicional, parecia não existir, hoje tornou-se, para muitos professores, um empecilho permanente à efetivação do seu trabalho em sala de aula. Os alunos não sabem ouvir, não respeitam a sua vez de falar, não obedecem ordens, não respeitam as mais básicas normas de conivência. Não raras as vezes, o professor se vê obrigado a deixar de lado o que havia planejado para desenvolver em aula, para contornar problemas de disciplina, tentando ensinar ao aluno o que ele já deveria saber, considerando que, por volta de seis anos, quando ele vai à escola, já tem uma larga vivência em família e em sociedade. Dessa forma, é lícito pensar que a família não está cumprindo com a sua parte na educação das crianças e dos adolescentes, transferindo para a escola funções que ultrapassam o âmbito pedagógico.

De acordo com a Carta Constitucional, artigo 205, "A educação, direito de todos e dever do Estado e da família, será promovida e incentivada com a colaboração da sociedade, visando ao pleno desenvolvimento da pessoa, seu preparo para o exercício da cidadania e sua qualificação para o trabalho" (Constituição Federativa do Brasil, 1988, p.38.). Porém a realidade nos mostra que há uma larga distância entre o que reza a lei e o que acontece, principalmente na escola, que está sendo obrigada a assumir um papel que de fato não Ihe caberia, sobrecarregando o professor e, provavelmente, comprometendo e desvirtuando o seu verdadeiro papel.

AQUINO (1996:p.46), em estudo realizado em 1995, sobre as representações de professores e alunos de escolas públicas e particulares de primeiro, segundo e terceiro graus, constatou que a escola, raras vezes, é representada, nas 
expectativas de seus agentes e clientela, como espaço de (re) produção científica e cultural. Ao contrário, o grande sentido do trabalho escolar parece ser a normatização de atitudes. É preocupante constatarmos que à escola parece ser atribuído somente o papel disciplinador, quando, na verdade, o seu objetivo primeiro é a reposição e a recriação do legado cultural.

Então a família falha, seja porque é desajustada, seja porque os pais não têm tempo de dedicar-se aos filhos, já que precisam trabalhar, e as necessidades são muitas para serem atendidas, visto que a sociedade nos estimula a "ter" cada vez mais, ou porque os pais não têm noção do quanto é importante para os filhos respeitar limites e colaborar com os outros, qualidades essenciais para uma sociedade sadia. A escola também falha quando impõe regras desnecessárias, que o aluno não entende porque tem que cumprir, como, por exemplo, o caso do uso do boné. Todos sabemos que ele faz parte do vestuário do adolescente de hoje; assim, não há por que considerá-lo desrespeitoso ou alegar que causaria problemas a alguém, principalmente porque às meninas é permitido usar chapéu ou touca em sala de aula. Outras regras também são absurdas, como obrigar o aluno a fazer toda a prova a lápis e depois passar a caneta, porque o professor não aceita nenhum tipo de rasura, nem o uso do corretor, e também não aceita a prova a lápis; então, o aluno, com medo que não dê tempo de passar a limpo, faz direto a caneta, sem a chance de corrigir algum erro, mesmo que perceba o equívoco - sem falar na proibição de ir ao banheiro durante a aula.

Não há como compreender esse tipo de regra, e o adolescente, saudavelmente, reage contra as normas impostas, principalmente porque não percebe nenhum sentido em obedecê-las. MCLAREN (1992:p.183), em estudo realizado em uma escola em Toronto, no Canadá, considerada a mais "barra pesada" da cidade, diz que os estudantes tinham consciência de que havia alguma lógica para algumas regras e convenções escolares e que, sem elas, se instalaria o caos e a confusão; porém também tinham consciência de que muitas regras eram desnecessárias e até idiotas. Isso significa que os adolescentes têm noção da importância das regras, sabem que elas são necessárias, desde que tenham sentido e legitimidade. 
Outro fator de mal-estar e revolta na sala de aula é o fato de que professor parece haver esquecido que a sua profissão, mais que qualquer outra, exige uma postura de educação e respeito, e que sua conduta deve estar acima de qualquer crítica. Logo, o professor, que já foi símbolo de educação, cortesia e respeito, lamentavelmente, hoje, nem sempre se comporta assim. Não é raro alguns professores atribuírem aos alunos adjetivos pejorativos como 'burro', 'ignorante', 'marginal' e muitos outros. É de se esperar que os tratando assim os alunos não os respeitem.

Há fatos que podem justificar essa situação, de acordo com ESTEVE (1995 :p 100),

\footnotetext{
“... o professor não pode afirmar que a sua tarefa se reduz apenas ao domínio cognitivo...pede-se que seja facilitador da aprendizagem, pedagogo eficaz, organizador do trabalho de grupo e que além do ensino cuide do equilíbrio psicológico e afetivo dos aluno, da integração social e da educação sexual, etc.; a tudo isto pode somar-se a atenção aos alunos especiais integrados na turma."
}

Pode-se perceber que as exigências são muitas, e as responsabilidades do professor aumentaram, porém a contrapartida em termos de compensação econômica, social e profissional não se efetivou. Não houve mudanças significativas na formação dos professores que lhes dessem respaldo para corresponder a essas exigências e, somando-se a isso, a desvalorização salarial trouxe como conseqüência a desvalorização social dos profissionais da educação. $\mathrm{Na}$ opinião de ESTEVE (1995:p.105), há poucos anos os professores, especialmente os que tinham formação universitária, gozavam de um elevado "status", social e cultural. Se, antes, a sua vocação e abnegação eram amplamente valorizadas, hoje, são os critérios econômicos que ditam a escala de valores, e a sua baixa remuneração o diminui perante a sociedade. Muitas vezes, ele é visto como alguém que foi incapaz de conseguir emprego melhor. Dessa forma, o salário se transforma em mais um agravante na crise de identidade que enfrentam os professores.

Considerando o que foi colocado a respeito do contexto profissional e social em que está inserido o professor e da rebeldia natural dos adolescentes, na 
ânsia de estabelecer sua própria identidade - às vezes agravada pela incapacidade dos pais em administrar esta fase de transição - é fácil entender por que a escola e a sala de aula se transformam, freqüentemente, em zona de conflito permanente. Porém o fato de a indisciplina dos alunos ser um problema que afeta, primeiramente, o professor não o faz ser o único responsável por buscar soluções.

Na concepção de AQUINO (1996:p.47), a escola e a família são as duas instituições responsáveis pela educação num sentido amplo. O processo educacional depende da articulação desses dois âmbitos institucionais. Um não substitui o outro; devem, sim, complementar-se. Se tanto a família como a escola são as principais responsáveis pela formação da criança ou do adolescente, é preciso que haja coerência entre princípios e valores de uma e outra, evitando confrontos entre professores e alunos e família e escola, o que favoreceria a rebeldia e a indisciplina dos alunos.

\section{CONSIDERAÇÕES FINAIS}

Não é pretensão deste artigo fornecer ao professores a solução definitiva para o problema da indisciplina, mesmo porque o filho/aluno/cidadão é responsabilidade da família, da escola e da sociedade.

Uma proposta que parece razoável e está ao alcance do professor é utilizar a avaliação como um meio para alunos e professores refletirem sobre a sua prática. Se ambos estão envolvidos no processo, não é justo que a avaliação seja unilateral, somente do professor em relação ao aluno. Nesta mesma linha de pensamento, PUGLISI (1988: p.48-49) coloca que "hasta ahora, la evaluación se ha cumplido exclusivamente en un solo sentido: el que va del educador al educando". Se a educação, entre outras coisas, supõe a interação entre o professor e o aluno, deveria existir uma relação recíproca. Portanto, para que a educação seja eficiente, deve abranger todos os envolvidos no processo.

Uma alternativa simples e evidente para avaliar de forma justa e, como conseqüência, resolver ou atenuar os problema de indisciplina na escola, seria 
pôr em prática, de maneira efetiva, o que diz a lei: a avaliação deve priorizar o aspecto qualitativo sobre o quantitativo. De acordo com HOFFMANN (1995:p 34), avaliar, sob o aspecto qualitativo, significa observar e interpretar de forma consistente as manifestações do aluno. Claro que isso não é tarefa fácil, se consideramos todo o contexto em que se encontram professor e aluno.

Mas, com certeza, há muito mais chance de o professor conseguir alguma mudança dos alunos se oferecer a eles um parecer a respeito das sua atitudes, convidando-os a falar e a opinar sobre a sua conduta e, principalmente, sugerindo que busquem soluções para os problemas de convivência que estão enfrentando - em vez de, simplesmente, atribuir uma nota ou um sinal de mais ou menos como resposta às atitudes dos alunos, sem refletir sobre elas. É necessário permitir que os alunos se auto-avaliem, tornando-os sujeitos da sua própria avaliação, responsabilizando-os, também, pela nota final que a eles terá que ser atribuída. Para MOSQUERA (1978: p.121), "o professor deve ajudar o aluno a sentir que aquilo que ele expressa tem valor", isso implica aceitá-lo com suas idéias e valores e permitir que, também, os alunos o avaliem, aceitar criticas e sugestões, porque pouco efeito surte a teoria dissociada da prática.

PERRENOUD (1993:p.173) sugere que uma mudança na avaliação, que afete realmente o sistema de ensino, deve ser de ser de caráter formativo, ou seja, ela deve ajudar o aluno a aprender e o professor a ensinar. Através da avaliação concebida como meio de reflexão e crescimento, é possível acreditar em mudanças significativas na disciplina em sala de aula, na aquisição de conhecimentos e, também, na possibilidade de um processo avaliativo mais justo, no qual todos sairão beneficiados, principalmente o jovem, que poderá utilizar esta prática nos demais setores da sua vida.

\section{BIBLIOGRAFIA}

AQUINO, Julio Groppa. A desordem na relação professor-aluno: Indisciplina, moralidade e conhecimento. In: AQUINO, Julio Groppa, org. Indisciplina na escola - Alternativas teóricas e práticas. São Paulo, SP: Summus editorial, 1996.

ESTEVE, José M. Mudanças sociais e função docente in: NÓVOA, Antonio. Profissão Professor. Portugal: Porto Editora. LDA, 1995. 
HOFFMANN, Jussara. Pontos e contrapontos: do pensar ao agir em avaliação. Porto Alegre: Mediação, 1998.

LUCKESI, Cipriano C. A avaliação da aprendizagem escolar. São Paulo: Cortez, 1999.

MCLAREN, Peter. Rituais na Escola - Em direção a uma economia política de símbolos e gestos na educação Petrópolis, RJ: Vozes,1992.

MENEGOLLA, Maximiliano. E agora escola? Petrópolis, RJ: Vozes, 1992.

MOSQUERA, Juan. O professor como pessoa. Porto Alegre: Sulina, 1978.

PERRENOUD, Philippe. Não mexam na minha avaliação! Para uma abordagem sistêmica da mudança pedagógica. In ESTRELA, Albano, NÓVOA Antônio. A avaliação em educação: novas perspectivas. Portugal: Porto Editora, 1993.

PUGLISI, Alfio, A. Revista de Educación La Obra. N. 11. Buenos Aires: Ediciones La Obra, 1988.

SANT'ANNA, Ilza Martins. Porque avaliar? Como avaliar? Critérios e instrumentos. Petrópolis, RJ: Vozes, 1995. 